\title{
RIPK1 regulates the survival of human melanocytes upon endoplasmic reticulum stress
}

\author{
XUECHENG SUN ${ }^{*}$, TAO WANG ${ }^{*}$, BO HUANG, GAOBO RUAN and AIE XU \\ Department of Dermatology, The Third People's Hospital of Hangzhou, Hangzhou, Zhejiang 310009, P.R. China
}

Received June 19, 2019; Accepted January 22, 2020

DOI: $10.3892 /$ etm.2020.8575

\begin{abstract}
Vitiligo is a common congenital or acquired disfiguring skin disorder. At present, endoplasmic reticulum (ER) stress has been identified to serve a critical role in the pathogenesis of vitiligo. Receptor-interacting serine/threonine-protein kinase 1 (RIPK1) is a protein serine/threonine kinase. The specific molecular mechanism of RIPK1 in human melanocytes upon ER stress remains to be determined. In the present study, RIPK1 was significantly downregulated in tunicamycin (TM)-induced ER stressed-human melanocytes. Subsequently, to explore the role of RIPK1 in ER stress-induced human melanocytes, human melanocytes were transfected with control or RIPK1 plasmids for $24 \mathrm{~h}$ and then treated with $3 \mu \mathrm{M}$ TM for 48 h. Reverse transcription-quantitative PCR and western blot analysis indicated that the expression levels of protein kinase R-like endoplasmic reticulum kinase, eukaryotic translation initiation factor 2 subunit 1 and CCAAT-enhancer-binding protein homologous protein were significantly increased in the TM-treated group compared with the controls. In addition, the effect of high RIPK1 expression on ER stress-induced human melanocyte survival was studied. The present results indicated that TM inhibited cell viability and promoted apoptosis in human primary epidermal melanocytes. Western blot analysis demonstrated that the expression of Bax and caspase- 3 was upregulated and the expression of $\mathrm{Bcl}-2$ was downregulated in TM-treated human melanocytes. The effects of TM on human melanocytes were reversed by RIPK1 overexpression. Therefore, RIPK1 overexpression may have an effect on the PI3K/AKT/mTOR signaling pathway in human melanocytes under ER stress. The results of the current study demonstrated that RIPK1 could protect human melanocytes from cell damage induced by ER stress by regulating the PI3K/AKT/mTOR and
\end{abstract}

Correspondence to: Dr Aie Xu, Department of Dermatology, The Third People's Hospital of Hangzhou, 38 Xihu Road, Hangzhou, Zhejiang 310009, P.R. China

E-mail: xa20191806@163.com

*Contributed equally

Key words: receptor-interacting serine/threonine-protein kinase 1, vitiligo, endoplasmic reticulum stress, human melanocytes
ER stress signaling pathways, thereby serving a protective role in the occurrence and development of vitiligo.

\section{Introduction}

Vitiligo is a common congenital or acquired disfiguring skin disorder related to melanocyte destruction. The incidence of vitiligo is $0.5-1.0 \%$ worldwide $(1,2)$, and causes the skin to lose its natural pigmentation (3). The incidence of vitiligo is not related to age, sex, skin type or ethnicity (4). The endoplasmic reticulum (ER) is an important organelle that is mainly responsible for protein biosynthesis, folding and the maintenance of cell homeostasis (5). However, under certain physiological and pathological conditions, protein folding may be severely impaired, causing ER stress (6). As a result, a specific ER stress response pathway will be activated, which can lead to apoptosis (7). Tyrosinase is a rate-limiting enzyme that catalyzes the production of melanin in melanocytes (8). Tyrosinase is critical for melanogenesis and plays a key role in a number of pigment-deficient diseases. Le Poole et al (9) indicated that vitiligo-related gene 1 expression was decreased in vitiligo patients compared with the healthy controls, which may be due to the transfer of tyrosinase in the ER, but the specific mechanism behind this process remain to be elucidated.

Receptor-interacting serine/threonine-protein kinase 1 (RIPK1) was first reported to serve a crucial role in necroptosis (10). Necroptosis is a form of programmed cell death in development, inflammation and tissue homeostasis (11). The function of necroptosis is to regulate downstream molecules through post-transcriptional modifications, including phosphorylation and ubiquitination (12). RIPK1 has a major impact on liver pathogenesis and liver disease prognosis $(13,14)$. Previous research has indicated that RIPK1-mediated necrotic apoptosis can also occur in neuronal cells, leading to neurodegenerative disease (15). However, to the best of our knowledge, the role of RIPK1 in vitiligo remains undetermined.

A previous study reported that the PI3K/AKT/mTOR pathway is associated with cell survival in response to oxidative stress (16). Growth factors may protect against oxidative stress-induced apoptosis through the activation of the AKT and mTOR pathways (17-19). Furthermore, another study suggested that $\alpha$-melanocyte-stimulating hormone stimulated melanogenesis through activating the mitogen-activated protein kinase kinase/ERK or PI3K/AKT pathways (20). Regulation of the PI3K/AKT/mTOR signaling pathway has 
been reported to be a novel approach for the clinical treatment of vitiligo (21). Moreover, the association between RIPK1 and the PI3K/AKT/mTOR pathway in melanocytes under ER stress remains largely unclear. Therefore, the present study aimed to explore the mechanisms of action of RIPK1 in ER-stressed human melanocytes.

\section{Materials and methods}

Cell culture and treatment. Human primary epidermal melanocytes were acquired from American Type Culture Collection. Cells were cultured in Medium 254 (Gibco; Thermo Fisher Scientific, Inc.) supplemented with human melanocyte growth supplement (Gibco; Thermo Fisher Scientific, Inc.) at $37^{\circ} \mathrm{C}$ and $5 \% \mathrm{CO}_{2}$.

To induce ER stress, human primary epidermal melanocytes $\left(1 \times 10^{6}\right.$ cells per well) were treated with $3 \mu \mathrm{M}$ tunicamycin (TM; Sigma-Aldrich; Merck KGaA) (22) at $37^{\circ} \mathrm{C}$ for 24,48 and $72 \mathrm{~h}$.

Primary epidermal melanocytes were transfected with $1 \mu \mathrm{g}$ control plasmid (cat no. sc-437275; Santa Cruz Biotechnology, Inc.) or $1 \mu \mathrm{g}$ RIPK1 plasmid (cat no. sc-422681-ACT; Santa Cruz Biotechnology, Inc.) for $24 \mathrm{~h}$ using Lipofectamine ${ }^{\circledR} 2000$ reagent (Invitrogen; Thermo Fisher Scientific, Inc.) in accordance with the manufacturer's protocol. Reverse transcription-quantitative PCR (RT-qPCR) and western blot analysis were used to detect the efficiency of cell transfection. $24 \mathrm{~h}$ after cell transfection, subsequent experiments were performed.

$R T-q P C R$. Total RNA was isolated from human primary epidermal melanocytes using TRIzol ${ }^{\circledR}$ reagent (Invitrogen; Thermo Fisher Scientific Inc.) and cDNA was synthesized using a High-Capacity cDNA Reverse Transcription kit (Applied Biosystems; Thermo Fisher Scientific, Inc.) following the manufacturer's protocol. The following thermocycling conditions were used: $70^{\circ} \mathrm{C}$ for $5 \mathrm{~min}, 37^{\circ} \mathrm{C}$ for $5 \mathrm{~min}$ and $42^{\circ} \mathrm{C}$ for $60 \mathrm{~min}$. Subsequently, qPCR was performed using the SYBR Green PCR Master Mix (Applied Biosystems; Thermo Fisher Scientific, Inc.). The following thermocycling conditions were used for the qPCR: Initial denaturation at $95^{\circ} \mathrm{C}$ for $5 \mathrm{~min} ; 40$ cycles of $95^{\circ} \mathrm{C}$ for $10 \mathrm{sec}$, $60^{\circ} \mathrm{C}$ for $20 \mathrm{sec}$ and a final extension at $72^{\circ} \mathrm{C}$ for $30 \mathrm{sec}$. The following primer pairs were used for the qPCR: GAPDH forward, 5'-TGTTGCCATCAATGACCCCTT-3' and reverse, 5'-CTC CACGACGTACTCAGCG-3'; RIPK1 forward, 5'-AGGCTT TGGGAAGGTGTCTC-3' and reverse, 5'-CGGAGTACTCAT CTCGGCTTT-3'; protein kinase R-like endoplasmic reticulum kinase (PERK) forward, 5'-TCCTGCTTTGCATCGTAGCC-3' and reverse, 5'-GATGGAAAAGCCTGCGCA-3'; eukaryotic translation initiation factor 2 subunit 1 (eIF2 $\alpha$ ) forward, 5'-CTC CTGAAAGCAGCAACCTC-3' and reverse, 5'-GACCGAGAT GAAGCATCGTG-3' and CCAAT/enhancer-binding protein epsilon (CHOP) forward, 5'-CTTCCATGTAGCGGAGTCCT-3' and reverse, 5'-GTGAGAGCCAGTCTCCCTTT-3'. Relative gene expression was quantified using the $2^{-\Delta \Delta \mathrm{Cq}}$ method (23). GAPDH was used as the internal control.

Western blot analysis. Total protein was extracted using ice-cold RIPA buffer (Beyotime Institute of Biotechnology) according to the manufacturer's protocol. BCA assays (Thermo Fisher Scientific, Inc.) were used to measure the protein concentrations. Protein samples (40 $\mu \mathrm{g} /$ lane) were separated by $12 \%$ SDS-PAGE and transferred to PVDF membranes (EMD Millipore). The membranes were blocked with 5\% skim milk in TBS containing $0.1 \%$ Tween for $2 \mathrm{~h}$ at room temperature. The membranes were then incubated with the following primary antibodies: RIPK1 (cat. no. 3493; 1:1,000; Cell Signaling Technology, Inc.), PERK (cat. no. 5683; 1:1,000; Cell Signaling Technology, Inc.), eIF2 $\alpha$ (cat. no. 5324; 1:1,000; Cell Signaling Technology, Inc.), CHOP (cat no. 2895; 1:1,000; Cell Signaling Technology, Inc.), caspase-3 (cat. no. 14220; 1:1,000; Cell Signaling Technology, Inc.), Bcl-2 (cat. no. 3498; 1:1,000; Cell Signaling Technology, Inc.), Bax (cat. no. 5023; 1:1,000; Cell Signaling Technology, Inc.), phospho (p)-AKT (cat. no. 4060; 1:1,000; Cell Signaling Technology, Inc.), p-mTOR (cat. no. 5536; 1:1,000; Cell Signaling Technology, Inc.), p-PI3K (cat. no. BS4811; 1:1,000; Biogot Technology Co., Ltd.) and GAPDH (cat. no. 5174; 1:1,000; Cell Signaling Technology, Inc.) overnight at $4^{\circ} \mathrm{C}$. Subsequently, the membranes were incubated with horseradish peroxidase-conjugated anti-mouse/anti-rabbit Immunoglobulin G secondary antibodies (cat. nos. 7076 and 7074; 1:1,000; Cell Signaling Technology, Inc.) at room temperature for $2 \mathrm{~h}$. Protein bands were visualized by enhanced chemiluminescence (EMD Millipore). GAPDH was used as the loading control. ImageJ version 2.0 software (National Institutes of Health) was used to quantify the band intensity.

Flow cytometric analysis of apoptosis. Cell apoptosis was detected using the Annexin-V/propidium iodide (PI) Apoptosis Detection kit [cat. no. 70-AP101-100; Hangzhou Multi Sciences (Lianke) Biotech Co., Ltd.]. Human melanocytes were plated in six-well plates at a density of $2-3 \times 10^{5}$ cells per well overnight. Cells were then transfected with control or RIPK1 plasmids for $24 \mathrm{~h}$, followed by treatment with $3 \mu \mathrm{M} \mathrm{TM}$ for $48 \mathrm{~h}$. Cells were then collected by centrifugation $\left(1,000 \times \mathrm{g} ; 5 \mathrm{~min} ; 4^{\circ} \mathrm{C}\right)$, and resuspended in $100 \mu \mathrm{l}$ of FITC-binding buffer. Subsequently, the buffer was added to $5 \mu \mathrm{l}$ ready-to-use Annexin V-FITC (BD Biosciences) and $5 \mu \mathrm{l} \mathrm{PI}$. Cells were incubated in the dark for $30 \mathrm{~min}$ at room temperature. Annexin V-FITC and PI fluorescence were assessed using a BD FACSCalibur flow cytometer (BD Biosciences), and the data were analyzed using FlowJo software (version 7.6.1; FlowJo LLC).

MTT assay. Human melanocyte viability was determined using an MTT assay. Human melanocytes were plated in 96 -well plates at a density of $5 \times 10^{3}$ cells/well. Human melanocytes were transfected with control or RIPK1 plasmids for $24 \mathrm{~h}$ and then treated with $3 \mu \mathrm{M}$ TM for $48 \mathrm{~h}$. Subsequently, $20 \mu 1$ MTT reagent (Sigma-Aldrich; Merck KGaA) was added into each well for another $4 \mathrm{~h}$ at $37^{\circ} \mathrm{C}$. Subsequently, $150 \mu \mathrm{l}$ DMSO (Sigma-Aldrich; Merck KGaA) was added into each well and shaken for $15 \mathrm{~min}$. The optical density values were read at a wavelength of $490 \mathrm{~nm}$ using the FLUOstar ${ }^{\circledR}$ Omega Microplate Reader (BMG Labtech GmbH).

Statistical analysis. Data are presented as the mean \pm standard deviation of at least three independent experiments. One-way ANOVA followed by Tukey's post-hoc test was used for multiple comparisons. Unpaired Student's t-test was used to analyze the statistical significance between two groups. 
A

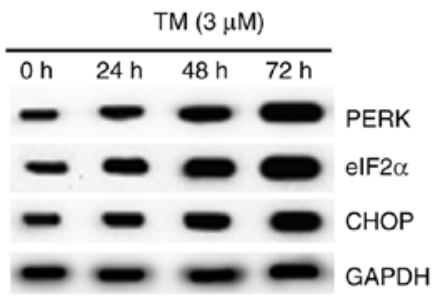

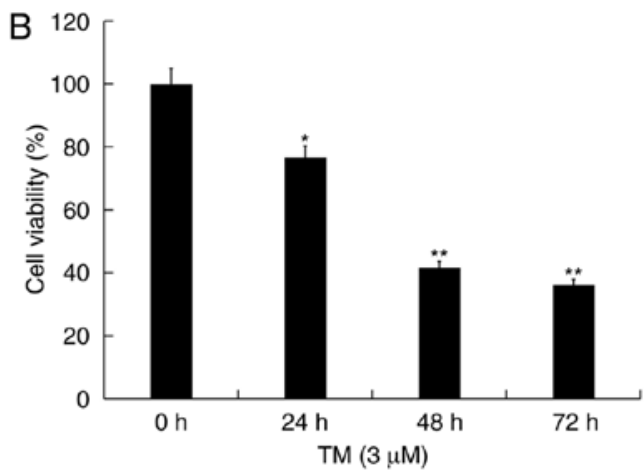

C

$\operatorname{TM}(3 \mu \mathrm{M})$
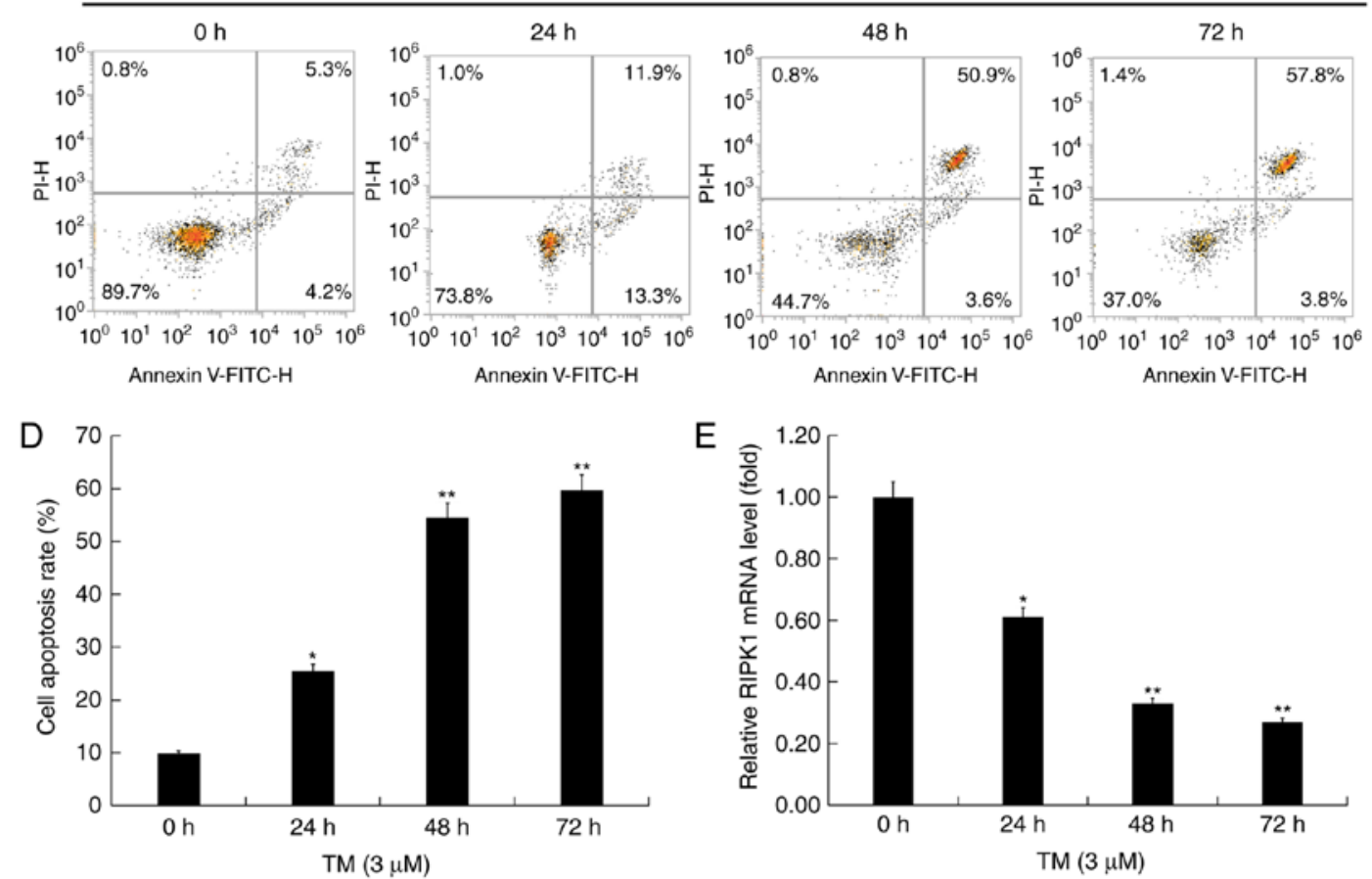

$\mathrm{E}$
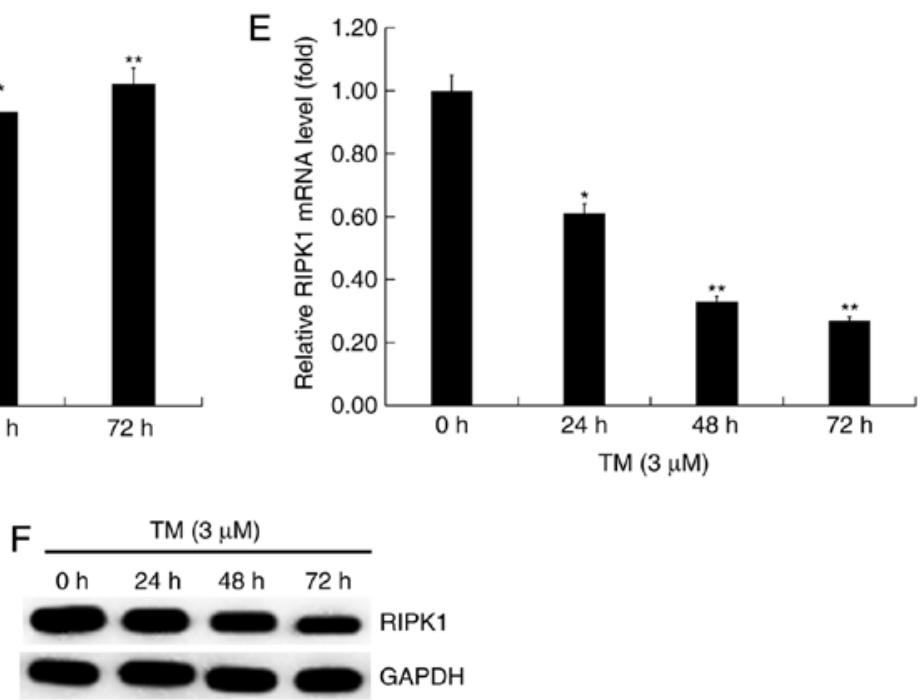

Figure 1. RIPK1 expression is downregulated with the increase of TM treatment time. (A) Western blot analysis was performed to detect the expression of PERK, eIF2 $\alpha$ and CHOP in human melanocytes treated with $3 \mu \mathrm{M}$ TM for 24, 48 or 72 h. (B) MTT assay was performed to detect cell viability. (C) Flow cytometry plots and (D) cell apoptosis rates of cells treated with $3 \mu \mathrm{M}$ TM. (E) Reverse transcription-quantitative PCR and (F) Western blot analysis were performed to detect RIPK1 expression. ${ }^{*} \mathrm{P}<0.05$ and ${ }^{* *} \mathrm{P}<0.01$ vs. 0 h TM treatment group. RIPK1, receptor-interacting serine/threonine-protein kinase 1 ; PERK, protein kinase R-like endoplasmic reticulum kinase; eIF2 $\alpha$, eukaryotic translation initiation factor 2 subunit 1; CHOP, CCAAT-enhancer-binding protein homologous protein; TM, tunicamycin.

$\mathrm{P}<0.05$ was considered to indicate a statistically significant difference.

\section{Results}

Expression of RIPK1 in human melanocytes induces ER stress. To explore the role of RIPK1 in ER stress-induced human melanocytes, cells were treated with $3 \mu \mathrm{M}$ TM for 24, 48 and 72 h. Firstly, the expression of ER stress-related proteins in human melanocytes induced by ER stress was investigated. Western blot analysis indicated that the expression of ER stress-related proteins, including PERK, eIF $2 \alpha$ and
CHOP was upregulated in a time-dependent manner (Fig. 1A), indicating that $3 \mu \mathrm{M}$ TM activated ER stress in human melanocytes. MTT assay indicated that TM significantly inhibited cell viability (Fig. 1B) and induced cell apoptosis (Fig. 1C and D) in a time-dependent manner in human melanocytes compared with the control. RT-qPCR and western blot analysis results indicated that RIPK1 expression decreased with the increase of TM treatment time (Fig. 1E and F). RIPK1 expression was decreased in human melanocytes induced by ER stress.

Transfection efficiency of RIPK1 plasmid in human melanocytes. Human melanocytes were transfected with control or 


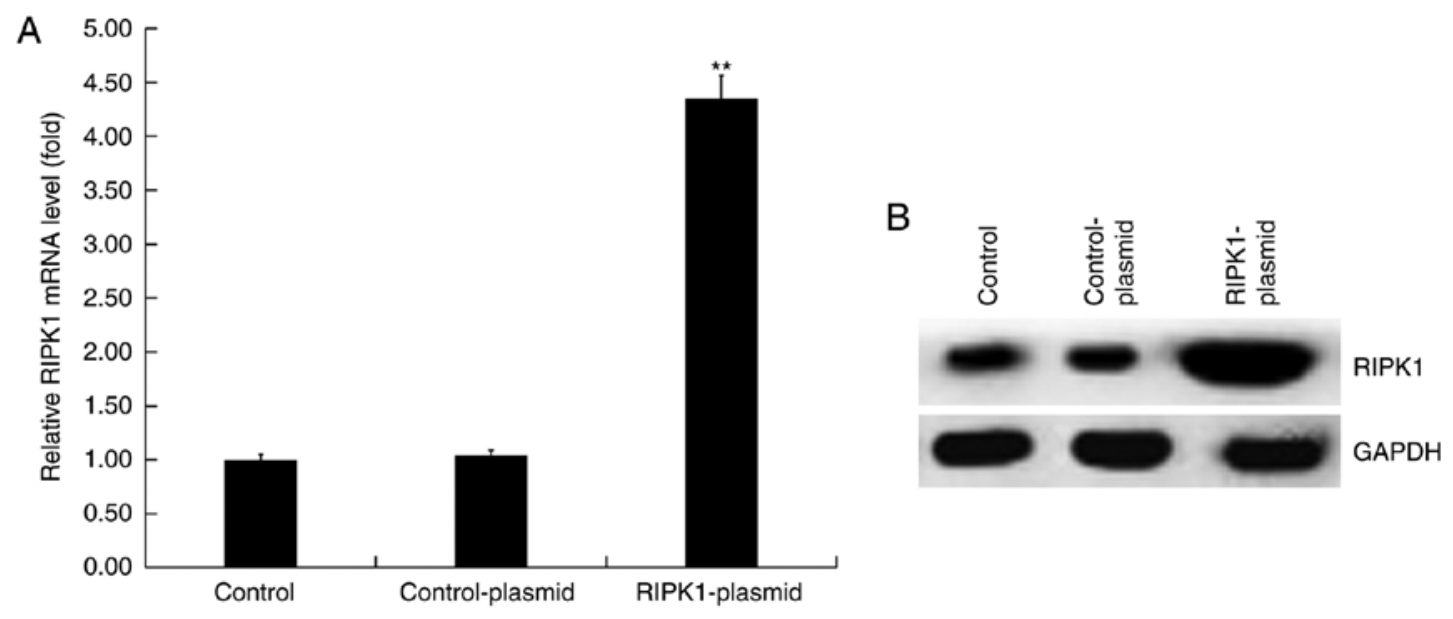

Figure 2. Transfection efficiency of RIPK1 plasmid in human melanocytes. (A) Reverse transcription-quantitative PCR and (B) western blot analysis were performed to detect the expression of RIPK1 in human melanocytes transfected with control or RIPK1 plasmids for $24 \mathrm{~h}$. " ${ }^{* *}<0.01 \mathrm{vs.} \mathrm{control} \mathrm{group.} \mathrm{RIPK1,}$ receptor-interacting serine/threonine-protein kinase 1.

A

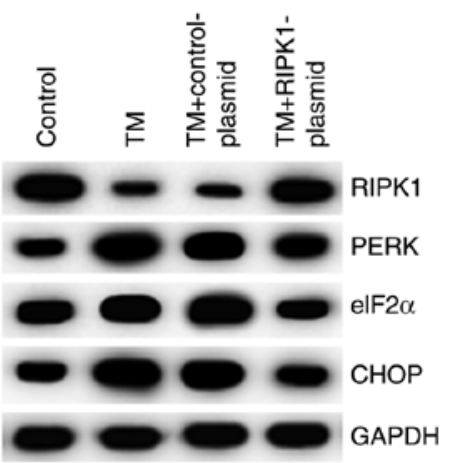

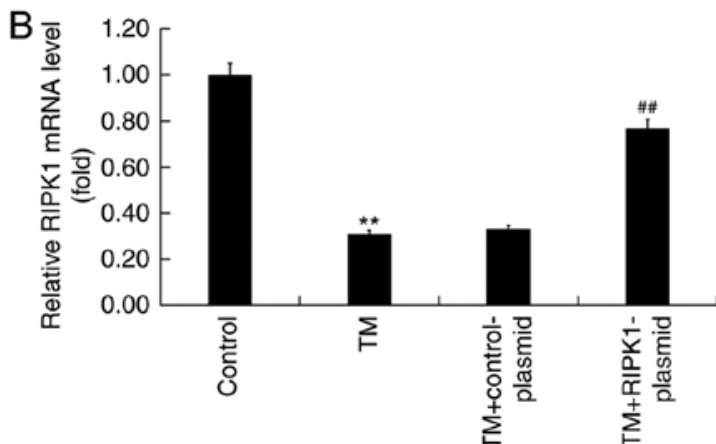

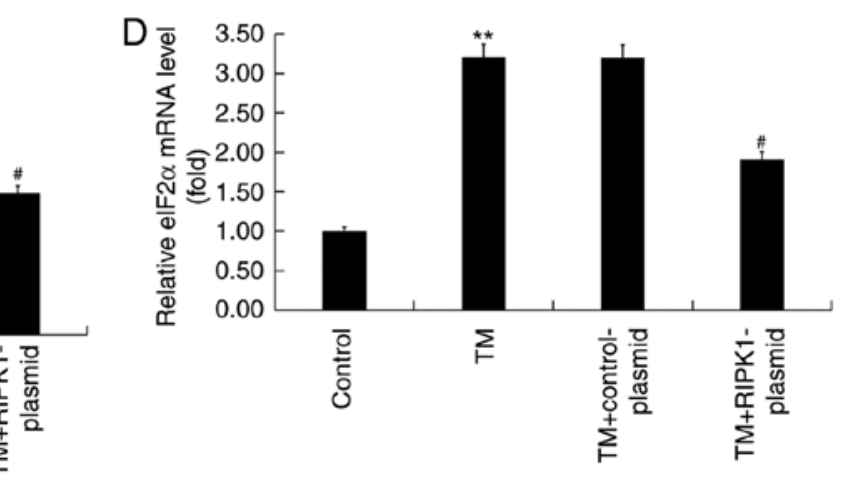

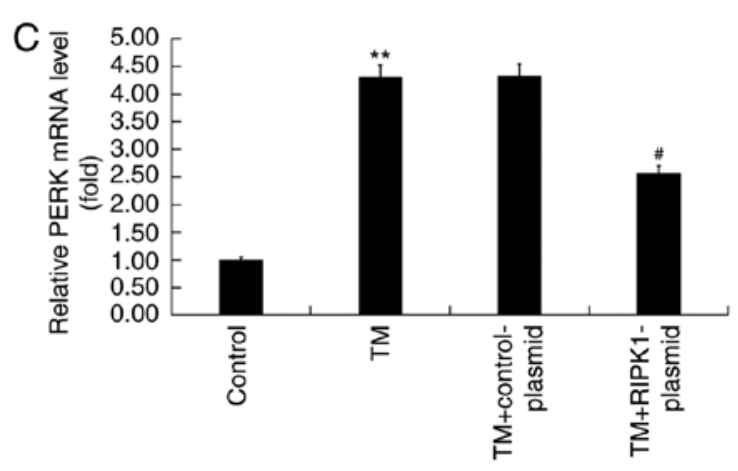

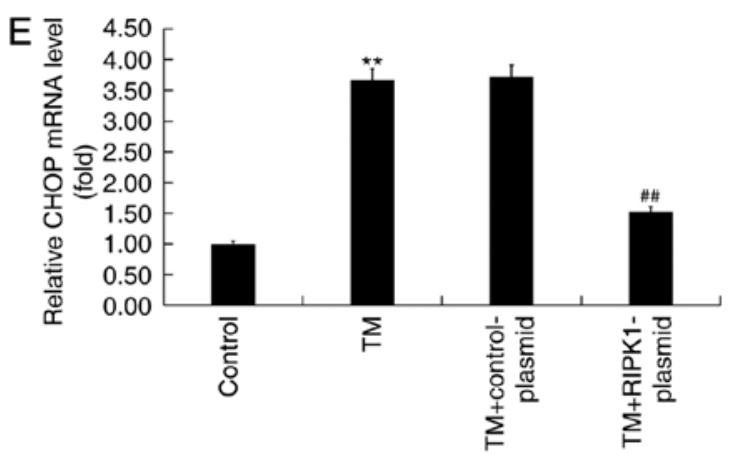

Figure 3. RIPK1 upregulation reduces the expression of endoplasmic reticulum stress-related proteins in human melanocytes. Human melanocytes were transfected with control or RIPK1 plasmids for $24 \mathrm{~h}$ and treated with $3 \mu \mathrm{M} \mathrm{TM}$ for $48 \mathrm{~h}$. (A) Western blot analysis was performed to detect the expression of RIPK1, PERK, eIF2 $\alpha$ and CHOP in human melanocytes. Reverse transcription-quantitative PCR was performed to detect the expression of (B) RIPK1, (C) PERK, (D) eIF2 $\alpha$ and (E) CHOP in human melanocytes at the mRNA level. ${ }^{* *} \mathrm{P}<0.01$ vs. control group; ${ }^{~} \mathrm{P}<0.05$ and ${ }^{\# \#} \mathrm{P}<0.01$ vs. TM treatment group. RIPK1, receptor-interacting serine/threonine-protein kinase 1; PERK, protein kinase R-like endoplasmic reticulum kinase; eIF2 $\alpha$, eukaryotic translation initiation factor 2 subunit 1; CHOP, CCAAT-enhancer-binding protein homologous protein; TM, tunicamycin. 


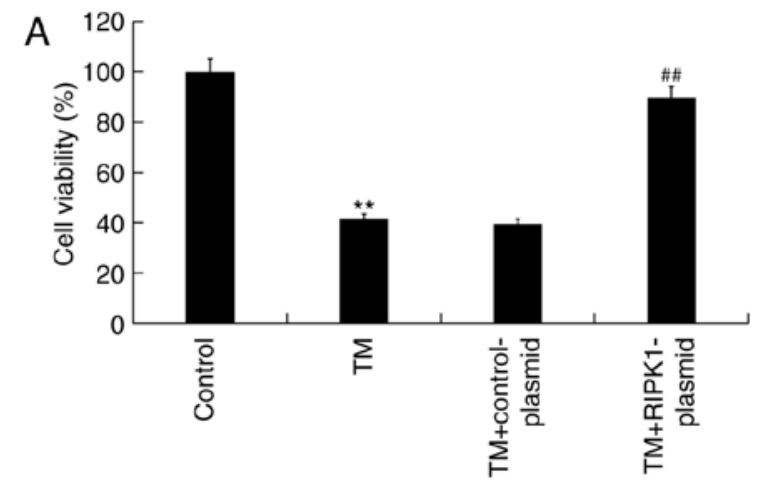

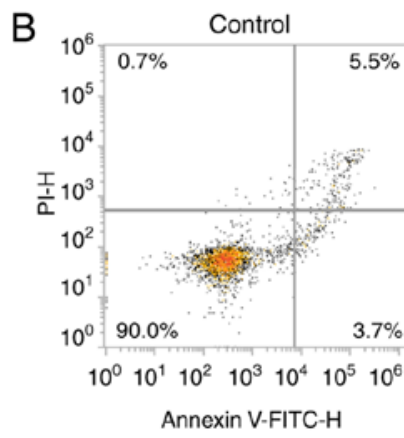

Annexin V-FITC-H

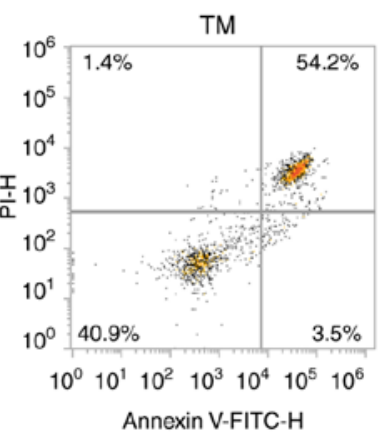

Annexin V-FITC-H
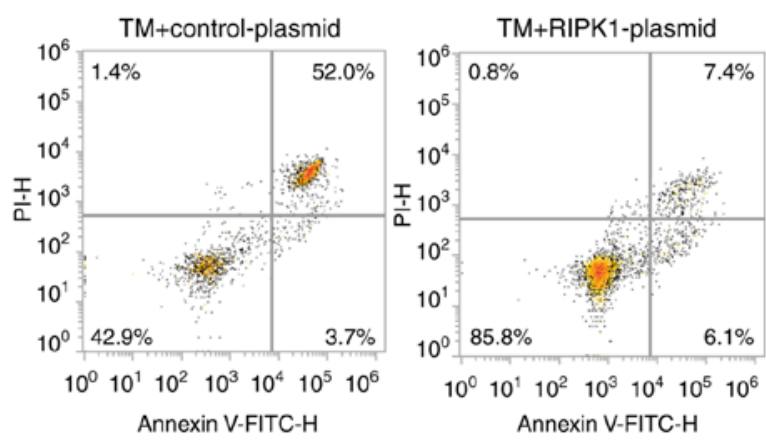

D

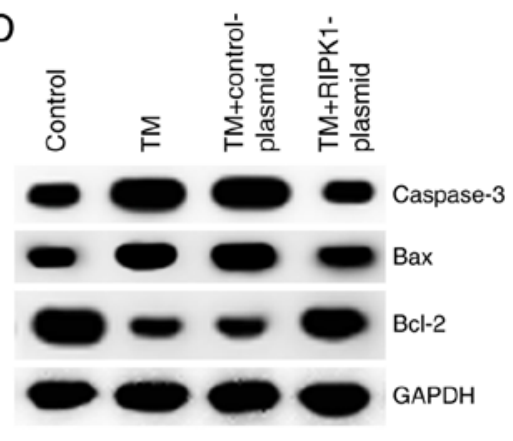

Figure 4. Effect of RIPK1 upregulation on the growth of human melanocytes induced by endoplasmic reticulum stress. Human melanocytes were transfected with control or RIPK1 plasmid for $24 \mathrm{~h}$ and treated with $3 \mu \mathrm{M}$ TM for $48 \mathrm{~h}$. (A) MTT assay was performed to investigate cell viability. (B) Flow cytometry plots and (C) cell apoptosis rates of cell. (D) Western blot analysis was performed to detect the expression of Bax, caspase-3 and Bcl-2 at protein level. ${ }^{* *} \mathrm{P}<0.01$ vs. control group; ${ }^{\# \#} \mathrm{P}<0.01$ vs. TM treatment group. RIPK1, receptor-interacting serine/threonine-protein kinase 1; TM, tunicamycin.

RIPK1 plasmids for $24 \mathrm{~h}$. RT-qPCR and western blot analysis were performed to detect transfection efficiency. RT-qPCR results demonstrated that compared with the control group, the mRNA expression of RIPK1 significantly increased in RIPK1 plasmid-transfected human melanocytes (Fig. 2A). Similar results were observed in the western blot analysis assay (Fig. 2B).

Effect of RIPK1 upregulation on the expression of ER stress-related proteins in human melanocytes. To investigate the effect of high RIPK1 expression on the expression of ER stress-related proteins in human melanocytes, the expression of PERK, eIF2 $\alpha$ and CHOP were examined using RT-qPCR and western blot analysis. The results revealed that RIPK1 protein expression decreased while PERK, eIF $2 \alpha$ and CHOP protein expression increased in the TM-treated group compared with the control group (Fig. 3A). Additionally, RIPK1 expression increased (Fig. 3A) while protein expression of PERK, eIF2 $\alpha$ and CHOP decreased in the TM + RIPK1-plasmid group compared with the TM-treated group (Fig. 3A). Similar results were observed in the RT-qPCR assays (Fig. 3B-E).

Effect of RIPK1 upregulation on the survival of ER stress-induced human melanocytes. The effect of high RIPK1 expression on the survival of ER stress-induced human melanocytes was investigated. MTT and flow cytometry assays revealed that compared with the control group, the cell viability of human melanocytes was significantly reduced, while cell apoptosis significantly increased in the TM treatment groups. RIPK1 plasmid transfection was indicated to significantly increase cell viability (Fig. 4A) and decrease cell apoptosis compared with the TM treatment groups (Fig. 4B and C). The expression of apoptosis-related proteins was also assessed. The results of western blot analysis indicated that compared with the control group, the protein expression of Bax and caspase- 3 increased while Bcl-2 expression decreased in the TM treatment group. RIPK1 plasmid transfection decreased 


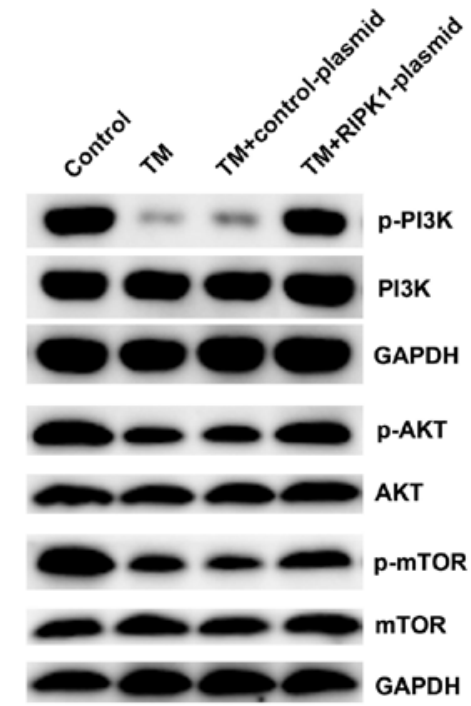

C

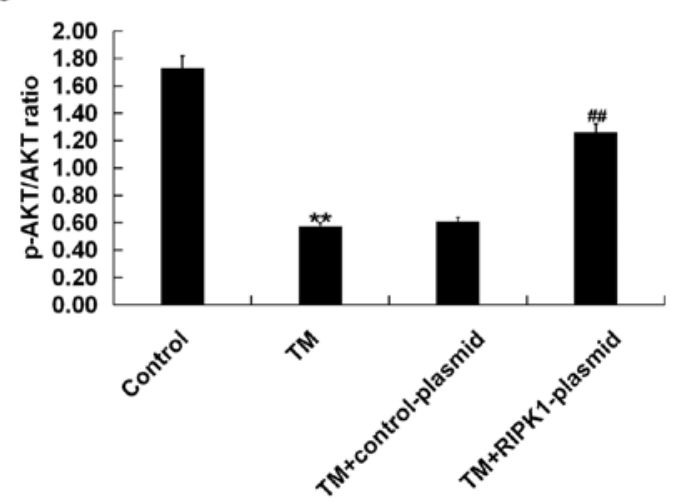

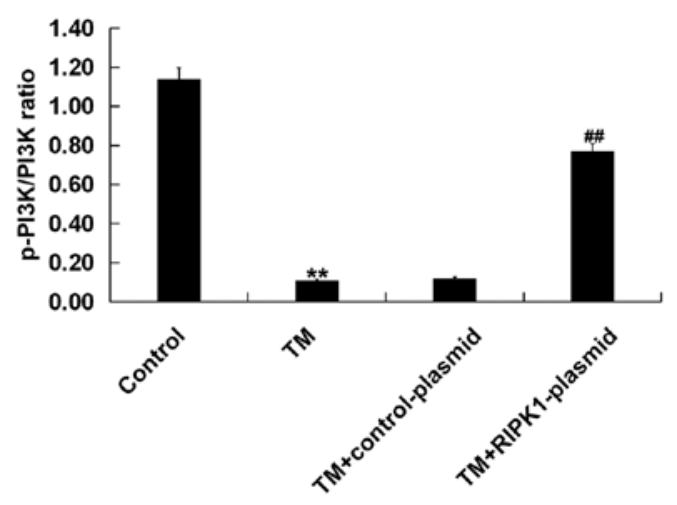

D

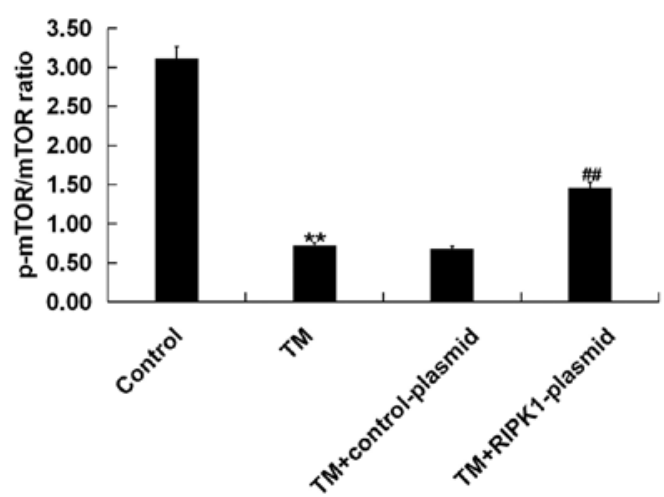

Figure 5. Relationship between high RIPK1 expression and the PI3K/AKT/mTOR signaling pathway in endoplasmic reticulum stress-induced human melanocytes. Human melanocytes were transfected with control or RIPK1 plasmids for $24 \mathrm{~h}$ and treated with $3 \mu \mathrm{M}$ TM for $48 \mathrm{~h}$. (A) Western blot analysis was performed to detect the expression of p-PI3K, p-AKT and p-mTOR. The relative protein levels of (B) p-PI3K, (C) p-AKT and (D) p-mTOR in human melanocytes. ${ }^{* *} \mathrm{P}<0.01$ vs. control group; ${ }^{\# \#} \mathrm{P}<0.01$ vs. TM treatment group. RIPK1, receptor-interacting serine/threonine-protein kinase 1; TM, tunicamycin; p-PI3K, phospho-PI3K; p-AKT, phospho-AKT; p-mTOR, phospho-mTOR.

Bax and caspase-3 protein expression and increased Bcl-2 protein expression compared with the TM treatment group (Fig. 4D). Therefore, overexpression of RIPK1 reversed cell growth inhibition induced by TM treatment.

Effect of RIPK1 upregulation on the PI3K/AKT/mTOR signaling pathway in human melanocytes. Western blot analysis demonstrated that compared with the control group, the protein expression of p-PI3K (Fig. 5A and B), p-AKT (Fig. 5A and C) and p-mTOR (Fig. 5A and D) significantly decreased in the TM treated group, but this effect was reversed by RIPK1 plasmid transfection (Fig. 5). Taken together, the results indicated that the effect of RIPK1 overexpression on human melanocyte growth may be associated with the $\mathrm{PI} 3 \mathrm{~K} / \mathrm{AKT} / \mathrm{mTOR}$ signaling pathway.

\section{Discussion}

Vitiligo is a common congenital or acquired skin disease that is characterized by loss of melanocytes, causing progressive skin depigmentation (24). Currently, vitiligo treatment mainly prevents disease development and achieves repigmentation in non-pigmented areas $(25,26)$. Phototherapy is currently the preferred method of vitiligo treatment, but corticosteroids, surgery or local immunomodulators are also used (27-29).

The ER stress response is a cellular process that can be aroused by different conditions that cause homeostatic imbalance (5). ER stress was reported to relate to the pathogenesis of a variety of diseases, including neurodegeneration, inflammation or cancer (30-33). Emerging evidence has suggested that pharmacological targeting of ER stress can be an effective therapeutic strategy for treating tumors (34-36). Different natural compounds induced ER stress-mediated death in cancer cells (37). ER stress was also identified to serve a critical role in the pathogenesis of vitiligo (38-40). However, to the best of our knowledge, the mechanism behind vitiligo pathogenesis caused by ER stress remains to be determined. In the present study, TM enhanced the protein expression of ER stress-related proteins PERK, eIF2 $\alpha$ and CHOP in a time-dependent manner. TM inhibited cell viability and induced apoptosis in human melanocytes.

RIPK1 is a crucial regulator of tumor necrosis factor receptor 1 signaling (41). RIPK1 regulates the balance between cell survival, apoptosis and necrotic apoptosis after the stimulation of tumor necrosis factor- $\alpha$ (42). In addition, several studies have indicated that RIPK1 promotes or inhibits 
the effector functions of caspase-8 and RIPK3 (43-45). In the present study, RIPK1 expression was demonstrated to be downregulated in human melanocytes induced by ER stress.

Previous studies have demonstrated that RIPK1 overexpression may lead to apoptosis in a number of cell types $(16,46)$. Luan et al (22) demonstrated that RIPK1 is important for the survival of melanoma cells undergoing pharmacological ER stress. The results of the present study showed that TM inhibited the survival of human melanocytes, but this effect was reversed by RIPK1 plasmid transfection. The $\mathrm{PI} 3 \mathrm{~K} / \mathrm{AKT} / \mathrm{mTOR}$ pathway has been indicated to be associated with cell survival in response to oxidative stress (20) and melanogenesis (17). Activation of the PI3K/AKT/mTOR pathway could reduce oxidative stress-induced apoptosis $(18,19)$. The present study explored whether the role of RIPK1 in melanocyte damage induced by oxidative stress was associated with the PI3K/AKT/mTOR pathway. ER stress-induced inhibition of the PI3K/AKT/mTOR signaling pathway in human melanocytes was significantly suppressed by RIPK1 overexpression.

In conclusion, RIPK1 may protect human melanocytes from cell damage induced by ER stress by regulating the $\mathrm{PI} 3 \mathrm{~K} / \mathrm{AKT} / \mathrm{mTOR}$ and ER stress signaling pathways. The results of the current study indicated that RIPK1 might protect melanocytes from ER stress induced damage. Therefore, RIPK1 might serve a protective role in the occurrence and development of vitiligo. The present research provides potential therapeutic targets and theoretical basis for the treatment of vitiligo. However, the present study is a preliminary study exploring the role of RIPK1 in vitiligo. To elucidate the role of RIPK1 in vitiligo further, future in-depth research is required. For example, the effect of RIPK1 on melanocytes from vitiligo patients should be investigated. The relationship between RIPK1 and PI3K/AKT/mTOR signaling pathway in human melanocytes also requires more in-depth research. The effect of RIPK1 in vitiligo should be investigated in vivo in the future.

\section{Acknowledgements}

Not applicable.

\section{Funding}

The present study was supported by the National Natural Science Foundation of China (grant no. 81773335, 81803131 and 81602755), Zhejiang Provincial Natural Science Foundation (grant no. LY18H110001) and Zhejiang Basic Public Welfare Research Project (grant no. LGF18H110002).

\section{Availability of data and materials}

All datasets used and/or generated during the present study are available from the corresponding author on reasonable request.

\section{Authors' contributions}

XS and TW contributed to study design, data collection, statistical analysis, data interpretation and manuscript preparation. $\mathrm{BH}, \mathrm{GR}$ and $\mathrm{AX}$ contributed to data collection and statistical analysis. All authors read and approved the final manuscript.

\section{Ethics approval and consent to participate}

Not applicable.

\section{Patient consent for publication}

Not applicable.

\section{Competing interests}

The authors declare that they have no competing interests.

\section{References}

1. Ezzedine K, Eleftheriadou V, Whitton $\mathrm{M}$ and van Geel N: Vitiligo. Lancet 386: 74-84, 2015.

2. Ezzedine K, Lim HW, Suzuki T, Katayama I, Hamzavi I, Lan CC Goh BK, Anbar T, Silva de Castro C, Lee AY, et al: Revised classification/nomenclature of vitiligo and related issues: The Vitiligo Global Issues Consensus Conference. Pigment Cell Melanoma Res 25: E1-E13, 2012.

3. Gawkrodger DJ, Ormerod AD, Shaw L, Mauri-Sole I, Whitton ME, Watts MJ, Anstey AV, Ingham J, Young K; Therapy Guidelines and Audit Subcommittee, British Association of Dermatologists, et al: Guideline for the diagnosis and management of vitiligo. Br J Dermatol 159: 1051-1076, 2018.

4. Speeckaert R and van Geel N: Vitiligo: An update on pathophysiology and treatment options. Am J Clin Dermatol 18: 733-744, 2017.

5. Schwarz DS and Blower MD: The endoplasmic reticulum: Structure, function and response to cellular signaling. Cell Mol Life Sci 73: 79-94, 2016.

6. Tabas I: Consequences of cellular cholesterol accumulation: Basic concepts and physiological implications. J Clin Invest 110: 905-911, 2002.

7. Oyadomari S and Mori M: Roles of CHOP/GADD153 in endoplasmic reticulum stress. Cell Death Differ 11: 381-389, 2004.

8. Gunia-Krzyżak A, Popiol J and Marona H: Melanogenesis inhibitors: Strategies for searching for and evaluation of active compounds. Curr Med Chem 23: 3548-3574, 2016.

9. Le Poole IC, Sarangarajan R, Zhao Y, Stennett LS, Brown TL, Sheth P, Miki T and Boissy RE: 'VIT1', A novel gene associated with vitiligo. Pigment Cell Res 14: 475-484, 2001.

10. Huang H, Chen T, Zhou Y, Geng L, Shen T, Zhou L and Zheng S: RIPK1 inhibition enhances pirarubicin cytotoxic efficacy through AKT-P21-dependent pathway in hepatocellular carcinoma. Int J Med Sci 15: 1648-1657, 2008.

11. Linkermann A and Green DR: Necroptosis. N Engl J Med 370: 455-465, 2004.

12. Galluzzi L, Kepp O, Chan FK and Kroemer G: Necroptosis: Mechanisms and relevance to disease. Annu Rev Pathol 12: 103-130, 2017.

13. Schneider AT, Gautheron J, Feoktistova M, Roderburg C, Loosen SH, Roy S, Benz F, Schemmer P, Büchler MW, Nachbur U, et al: RIPK1 suppresses a TRAF2-dependent pathway to liver cancer. Cancer Cell 31: 94-109, 2017.

14. Saeed WK and Jun DW: Necroptosis: An emerging type of cell death in liver diseases. World J Gastroenterol 20: 12526-12532, 2014.

15. Shan B, Pan H, Najafov A and Yuan J: Necroptosis in development and diseases. Genes Dev 32: 327-340, 2018.

16. Cao $\mathrm{C}$ and Wan Y: Parameters of protection against ultraviolet radiation-induced skin cell damage. J Cell Physiol 220: 277-284, 2009.

17. Cao C, Huang X, Han Y, Wan Y, Birnbaumer L, Feng GS, Marshall J, Jiang M and Chu WM: Galpha(i1) and Galpha(i3) are required for epidermal growth factor-mediated activation of the Akt-mTORC1 pathway. Sci Signal 2: ra17, 2009.

18. Cao C, Lu S, Jiang Q, Wang WJ, Song X, Kivlin R, Wallin B, Bagdasarian A, Tamakloe T, Chu WM, et al: EGFR activation confers protections against UV-induced apoptosis in cultured mouse skin dendritic cells. Cell Signal 20: 1830-1838, 2008. 
19. Cheng LB, Cheng L, Bi HE, Zhang ZQ, Yao J, Zhou XZ and Jiang Q: Alpha-melanocyte stimulating hormone protects retinal pigment epithelium cells from oxidative stress through activation of melanocortin 1 receptor-Akt-mTOR signaling. Biochem Biophys Res Commun 443: 447-452, 2014.

20. Kadekaro AL, Kavanagh R, Kanto H, Terzieva S, Hauser J, Kobayashi N, Schwemberger S, Cornelius J, Babcock G, Shertzer HG, et al: Alpha-Melanocortin and endothelin-1 activate antiapoptotic pathways and reduce DNA damage in human melanocytes. Cancer Res 65: 4292-4299, 2005.

21. Wan J, Lin F, Zhang W, Xu A, DeGiorgis J, Lu H and Wan Y: Novel approaches to vitiligo treatment via modulation of mTOR and NF- $\mathrm{KB}$ pathways in human skin melanocytes. Int J Biol Sci 13: 391-400, 2017.

22. Luan Q, Jin L, Jiang CC, Tay KH, Lai F, Liu XY, Liu YL, Guo ST, Li CY, Yan XG, et al: RIPK1 regulates survival of human melanoma cells upon endoplasmic reticulum stress through autophagy. Autophagy 11: 975-994, 2015.

23. Livak KJ and Schmittgen TD: Analysis of relative gene expression data using real-time quantitative PCR and the 2(-Delta Delta C(T)) method. Methods 25: 402-408, 2001.

24. Le Poole IC, Das PK, van den Wijngaard RM, Bos JD and Westerhof W: Review of the etiopathomechanism of vitiligo: A convergence theory. Exp Dermatol 2: 145-153, 1993.

25. Speeckaert R and van Geel N: Vitiligo: An update on pathophysiology and treatment options. Am J Clin Dermatol 18: 733-744, 2017.

26. Gawkrodger DJ, Ormerod AD, Shaw L, Mauri-Sole I, Whitton ME, Watts MJ, Anstey AV, Ingham J and Young K Vitiligo: Concise evidence based guidelines on diagnosis and management. Postgrad Med J 86: 466-471, 2010.

27. Gianfaldoni S, Wollina U, Tirant M, Tchernev G, Lotti J, Satolli F, Rovesti M, Franca K and Lotti T: Herbal compounds for the treatment of vitiligo: A review. Open Access Maced J Med Sci 6 : 203-207, 2018

28. Lotti T, Wollina U, Tchernev G, Valle Y, Lotti J, França K, Satolli F, Rovesti M, Tirant M, Lozev I, et al: An innovative therapeutic protocol for vitiligo: Experience with the Use of Fraxel Herbium laser, topical latanoprost and successive irradiation with UVA-1 laser. Open Access Maced J Med Sci 6: 49-51, 2018.

29. Wang M and Kaufman RJ: Protein misfolding in the endoplasmic reticulum as a conduit to human disease. Nature 529: 326-335, 2016.

30. Bu Y and Diehl JA: PERK integrates oncogenic signaling and cell survival during cancer development. J Cell Physiol 231: 2088-2096, 2016.

31. Ivanova EA and Orekhov AN: The role of endoplasmic reticulum stress and unfolded protein response in atherosclerosis. Int $\mathrm{J}$ Mol Sci 17: pii: E193, 2016.

32. Keestra-Gounder AM, Byndloss MX, Seyffert N, Young BM, Chávez-Arroyo A, Tsai AY, Cevallos SA, Winter MG, Pham OH, Tiffany CR, et al: NOD1 and NOD2 signalling links ER stress with inflammation. Nature 532: 394-397, 2016.
33. Schonthal AH: Pharmacological targeting of endoplasmic reticulum stress signaling in cancer. Biochem Pharmacol 85: 653-666, 2013

34. Maurel M, McGrath EP, Mnich K, Healy S, Chevet E and Samali A: Controlling the unfolded protein response-mediated life and death decisions in cancer. Semin Cancer Biol 33: 57-66, 2015.

35. Schonthal AH: Endoplasmic reticulum stress: Its role in disease and novel prospects for therapy. Scientifca (Cairo) 2012: 857516, 2012.

36. Pereira DM, Valentão P, Correia-da-Silva G, Teixeira N and Andrade PB: Translating endoplasmic reticulum biology into the clinic: A role for ER-targeted natural products? Nat Prod Rep 32: 705-722, 2015

37. Park K, Lee SE, Shin KO and Uchida Y: Insights into the role of endoplasmic reticulum stress in skin function and associated diseases. FEBS J 286: 413-425, 2019.

38. Manga P, Elbuluk N and Orlow SJ: Recent advances in understanding vitiligo. F1000Res 5: pii: F1000 Faculty Rev-2234, 2016.

39. Guan C, Xu W, Hong W, Zhou M, Lin F, Fu L, Liu D and Xu A: Quercetin attenuates the effects of $\mathrm{H} 2 \mathrm{O} 2$ on endoplasmic reticulum morphology and tyrosinase export from the endoplasmic reticulum in melanocytes. Mol Med Rep 11: 4285-4290, 2015.

40. Pasparakis M and Vandenabeele P: Necroptosis and its role in inflammation. Nature 517: 311-320, 2015.

41. Silke J, Rickard JA and Gerlic M: The diverse role of RIP kinases in necroptosis and inflammation. Nat Immunol 16: 689-697, 2016.

42. Amin P, Florez M, Najafov A, Pan H, Geng J, Ofengeim D, Dziedzic SA, Wang H, Barrett VJ, Ito Y, et al: Regulation of a distinct activated RIPK1 intermediate bridging complex I and complex II in TNFo-mediated apoptosis. Proc Natl Acad Sci USA 115: E5944-E5953, 2018.

43. Orozco S, Yatim N, Werner MR, Tran H, Gunja SY, Tait SW Albert ML, Green DR and Oberst A: RIPK1 both positively and negatively regulates RIPK3 oligomerization and necroptosis. Cell Death Differ 21: 1511-1521,2014.

44. Rickard JA, O'Donnell JA, Evans JM, Lalaoui N, Poh AR, Rogers T, Vince JE, Lawlor KE, Ninnis RL, Anderton H, et al: RIPK1 regulates RIPK3-MLKL-driven systemic inflammation and emergency hematopoiesis. Cell 157: 1175-1188, 2014.

45. Tenev T, Bianchi K, Darding M, Broemer M, Langlais C, Wallberg F, Zachariou A, Lopez J, MacFarlane M, Cain K and Meier P: The Ripoptosome, a signaling platform that assembles in response to genotoxic stress and loss of IAPs. Mol Cell 43: 432-448, 2011.

46. Park S, Hatanpaa KJ,Xie Y, Mickey BE, Madden CJ, Raisanen JM, Ramnarain DB, Xiao G, Saha D, Boothman DA, et al: The receptor interacting protein 1 inhibits 553 induction through NF-kappaB activation and confers a worse prognosis in glioblastoma. Cancer Res 69: 2809-2816, 2009.

(i) $\ominus$ This work is licensed under a Creative Commons Attribution-NonCommercial-NoDerivatives 4.0 International (CC BY-NC-ND 4.0) License. 